\title{
Formal and Functional Differences between Differential Object Marking and Differential R Marking: Unity or Disunity?
}

\author{
Seppo Kittilä \\ University of Helsinki, Helsinki, Finland. \\ Email: kittila@mappi.helsinki.fi \\ Received June 23 ${ }^{\text {rd }}$, 2011; revised August $2^{\text {nd }}$, 2011; August $9^{\text {th }}, 2011$.
}

\begin{abstract}
A number of studies (see e.g. Bossong, 1985; Aissen, 2003; Næss, 2003) have shown that the marking of objects is influenced by animacy and definiteness. The effects of animacy are not confined to the marking of direct objects only, but the marking of Recipients/Goals is also determined by animacy in many languages. The phenomenon is labeled as Differential R/Goal Marking (DRM) by Haspelmath (2005) and Kittilä (2008). Even though both DOM and DRM are governed by animacy (and also definiteness), the two phenomena display both formal and functional differences. For example, disambiguation, which can be claimed to be the triggering factor of DOM in many languages, is clearly less relevant to DRM. These formal and functional differences between DOM and DRM will be discussed in this paper. The problem will be studied in light of three formal and four functional features. In light of the discussed features, it will be shown that DOM and DRM should not be seen as a uniform phenomenon, but they display evident differences.
\end{abstract}

Keywords: Differential OBJECT Marking, Animacy, Argument Marking

\section{Introduction}

Typically Differential Object Marking (DOM) is defined as a more elaborate marking of animate objects when compared to inanimate bearers of the same role. Canonical examples of DOM are found in (1) and (2):

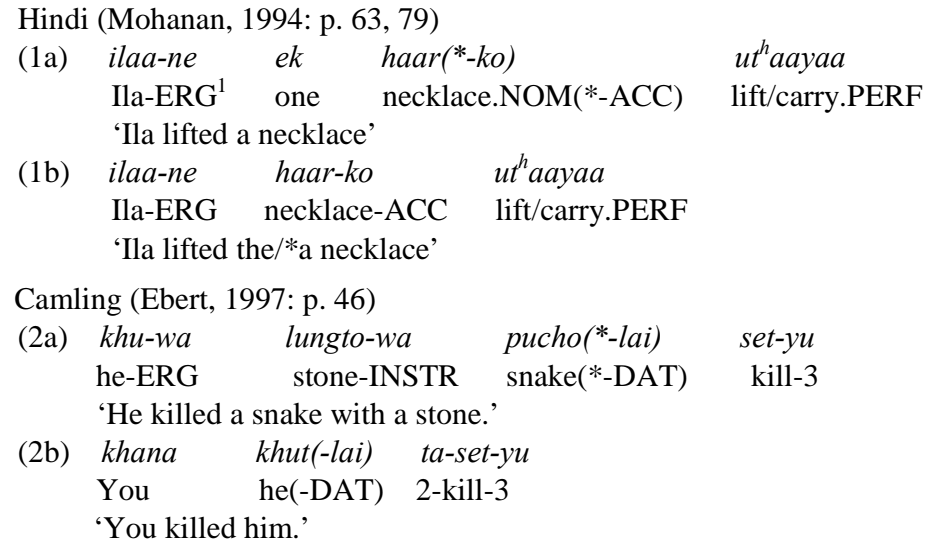

In (1) from Hindi, indefinite animate objects cannot bear accusative marking, while in (1b) the marking is obligatory. In (2), for its part, animate objects may never be marked, while animate (human) objects may optionally take a dative affix attached to them. In both cases, animate/definite objects bear more explicit marking than inanimate/indefinite arguments in the same function, a feature typical of DOM.

DOM has been the topic of numerous studies (see e.g. Bossong 1985; Aissen 2003; Næss 2003 among many others). It is typical of these studies that they have focused on the marking of direct objects only. Only rather recently has there been more interest in animacy effects on indirect objects (Recipients/

${ }^{1}$ The list of abbreviations is found at the end of the paper before references. ${ }^{2}$ In this paper the label $\mathrm{R}$ (argument) is used for referring to indirect objects. The label comprises both animate R's (the teacher sent the book to the student) and inanimate R's (the teacher sent the student to the school).
Goals) ${ }^{2}$. Recent studies of the topic include Haspelmath (2007) and Kittilä (2008). The authors define the phenomena somewhat differently (see Section 2 for an elaboration), but they are both dealing with cases where the marking of $\mathrm{R}$ arguments is determined by animacy. An example of Differential R marking (DRM) is given in (3):

Nkore-Kiga (Taylor, 1985: p. 91, 110)

(3a) n-ka-ha omworo empiiha

1-rp-give poor-man money

'I gave the poor man some money.'

(3b) n-aa-ta ebitakuri omu nyungu

1-tp-put potatoes in pot

'I put the potatoes in the pot.'

In Nkore-Kiga, animate R's are zero marked, as shown in (3a). Inanimate R's, in turn, receive prepositional coding illustrated in (3b). There are differences in the semantic roles borne 
by R in (3), but similarly to DOM, different instances of R can also be distinguished based on animacy. In other words, we can define $\mathrm{R}$ as a general Goal of transfer that can be either animate or inanimate depending on context.

In my paper, I will discuss differential marking of objects from a broader perspective than is typical of studies dealing with DOM. This means that I will combine DOM and DRM and discuss their similarities and differences. My goal is to show that differential marking of objects is not a uniform phenomenon, but DOM and DRM represent two rather closely related, yet different phenomena. They display both formal and functional differences. Moreover, DRM as a phenomenon is split and the first type of DRM resembles the other type of DRM formally, while functionally it is closer to DOM. This has good reasons, as will be shown below. I have confined the dis- cussion to cases, where animacy and/or definiteness can be seen as the primary triggering factor of the attested changes. As is generally known, marking of objects (both direct and indirect) is influenced by other features as well, such as affectedness and aspect (see e.g. Næss, 2007 for direct objects and Kittilä, 2007 for indirect objects), but these are not considered in this paper.

The organization of the paper is as follows. In Section 2, I will illustrate the discussed phenomena briefly. Section 3 discusses the formal differences of DOM and DRM, while in Section 4 the similarities and differences will be discussed from a functional perspective. Section 5 discusses the most central findings of the paper.

\section{The Phenomena}

As noted above, the label DOM is typically used for cases where animate/definite direct objects bear more explicit formal coding than inanimate/indefinite direct objects. Further examples of DOM are found in (4), (5):

Sinhala (Gair \& Paolillo, 1997: p. 32).

$\begin{array}{ll}\text { (4a) siri gunpaale*(-te) } & \text { gcehuwa } \\ \text { PN PN-DAT } & \text { hit } \\ \text { 'Siri hit Gunapala } & \\ \text { (4b) mame ee pote }\left({ }^{*} \text {-we }\right) & \text { kiyewwa } \\ \text { I tI book }(* \text {-ACC }) & \text { read } \\ \text { 'I read that book' } & \end{array}$

Badaga (Lazard, 1998: p. 189, cited from Pilot-Raichoor, 1991, 1994)
(5a) ama ondu manusa-na nooDida he a man-ACC see.PAST.3SG 'He saw a man.'

(5b) ama ondu kaTTE baNDi(-ya) nooDida he a wood vehicle(-ACC) see.PAST.3SG 'He saw a wagon'

In (4) and (5), animate objects bear more explicit marking than inanimate objects, which renders these canonical examples of DOM. The differences in animacy are marked somewhat differently. In Sinhala, inanimate objects are never marked, while in Badaga this is optional. The main principle, the (potentially) more explicit coding of animate objects is, however, the same for both languages.

DRM exhibits more heterogeneity than DOM and the phenomenon has been defined in two slightly different ways by two scholars working on similar phenomena independently of each other. First, Haspelmath (2007: p. 83) defines DRM as follows:

Special ("indirective" or "dative") R-marking is the more likely, the lower the $\mathrm{R}$ is on the animacy, definiteness and person scales.

An example of this is given in (6)

Drehu (Moyse-Faurie, 1983: pp. 161-162, as cited in Haspelmath, 2007: pp. 86-87)
(6a) Eni a hamëe angeic la itus. I PRES give him the book 'I give him the book.'
(6b) Eni a hamëë Wasinemu la itus. I PRES give Wasinemu the book 'I give Wasinemu the book.'

(6c) Enia hamëën la itus kowe la nekönatr. I PRES give the book to the child 'I give the book to the child.'

In Drehu, $\mathrm{R}$ appears in a zero marked form preceding $\mathrm{T}$ in case it outranks $\mathrm{T}$ in animacy, i.e. when $\mathrm{R}$ is a pronoun or a proper name. On the other hand, $\mathrm{R}$ receives adpositional coding if both $\mathrm{R}$ and $\mathrm{T}$ are nouns, and when $\mathrm{T}$ is definite, as in (6c).

In (6), the differential marking of $\mathrm{R}$ arguments is determined primarily by features of R. However, features of $\mathrm{T}$ are also relevant to $\mathrm{R}$ coding. In (6), prepositional coding of $\mathrm{R}$ occurs whenever $\mathrm{T}$ and $\mathrm{R}$ are both nouns (animacy per se does not seem to be relevant to the marking). The effects of $\mathrm{T}$ are more evident in (7):

Akan (Sáàh \& Ézè, 1997: p. 143f)

(7a) Ámá màà mè sìá

Ama give 1SG money

'Ama gave me money'

(7b) *Ámámàà mè siká nó

Ama give 1SG money the

(Ama gave me the money)

(7c) Ámá dè siká nó màà mè Ama take money the give $1 \mathrm{SG}$

'Ama gave me the money'

In Akan, a special serial verb construction is used if $\mathrm{T}$ is definite; $\mathrm{R}$ is preceded by the verb 'give', which can also be seen as a kind of prepositional marking.

In (6), (7), DRM is determined by properties of both $\mathrm{R}$ and $\mathrm{T}$. There are thus no significant changes in the semantic role borne by $\mathrm{R}$, but the variation follows, e.g., from ambiguity avoidance (especially in cases where both $\mathrm{T}$ and $\mathrm{R}$ are animate). This constitutes the decisive difference to the second type of DRM, where properties of $\mathrm{R}$ are alone responsible for the attested differences ${ }^{3}$. Consider

Korku (Nagaraja, 1999: p. 97)
(8a) raja
ra:ma-ke
sita-ke
ji-khe-nec
king.NOM
Ram-OBJ Sita-OBJ
give-PAST-PERS
'The king gave Sita to Ram.'

\footnotetext{
${ }^{3}$ Haspelmath discusses this under the label differential theme marking, but the two are in this paper viewed as differently motivated instances of the same phenomenon.
} 
(8b) iñj ini-koro-ken mya kama:y-Ten
I this-man-OBJ one work-ABL
'I sent that man to work in that village'

Balinese (I Wayan Arka, p.c.)

(9a) Guru-ne nto ngirim
teacher-DEF that AV.send
'The teacher sent a book to the person.'

(9b) Guru-ne nto ngirim teacher-DEF that AV.send 'The teacher sent a book to Indonesia.'

$$
\begin{array}{ll}
\text { Di-ga:w-en } & \text { kul-khe-nej } \\
\text { that-village-LOC } & \text { send-PAST-PERS }
\end{array}
$$

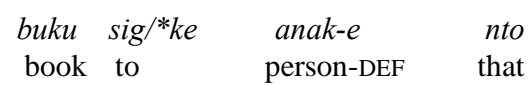

$\begin{array}{ccc}\text { buku } & k e / *^{*} \text { sig } & \text { Indonesia } \\ \text { book } & \text { to } & \text { Indonesia }\end{array}$

In (8), $\mathrm{T}$ is consistently animate, while in (9), the referent of $\mathrm{T}$ is invariably inanimate. On the other hand, there are evident differences in the referent of R. In (a), R is animate, while in (b), $\mathrm{R}$ is inanimate. In Korku, the variation is between a core argument ( $\mathrm{R}$ marked like the direct object) and an oblique. In Balinese, the differences are manifested via the preposition used for $\mathrm{R}$ coding; sig precedes animate R's, while $k e$ is used for marking inanimate R's. The mechanisms used for coding $\mathrm{R}$ arguments are different in Korku and Balinese (cases vs. adpositions), but the languages have in common that animacy determines the coding of R's.

\section{Formal Differences}

\section{Preliminaries}

In this section, I will discuss the formal differences between DOM and DRM from a formal perspective. The differences will be discussed in light of 3 features, namely:

1) The differences between zero and overt coding of objects

2) The differences in the syntactic status of arguments (arethey parts of clause core or clause periphery)

3) Optionality of the differences

The formal features will be discussed in the order they appear above.

\section{Differences in Zero vs. Explicit Marking of Objects}

DOM and DRM display evident differences in the role of zero vs. explicit marking of animate and inanimate objects. As shown in (4) and (5), in DOM either animate or inanimate objects (in the vast majority of cases, inanimate objects) are zero marked, while the other objects (usually the animate/definite objects) bear more elaborate coding. A further example is given in (10) (see also (1), (4), (5):
Amharic (Gasser, 1983: p. 110).

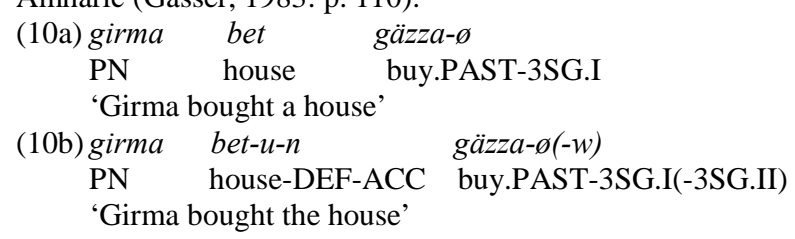

In (1), (4), (5) and (10), inanimate (and/or indefinite) objects are zero-marked, while animate (and/or definite) objects bear explicit coding. The languages, however, vary according to the obligatoriness vs. optionality of the explicit formal coding. For example, in Badaga human objects are obligatorily marked, while inanimate objects optionally bear accusative case. In Camling, in turn, objects ranking high for animacy may be marked, but less animate (non-human) objects never receive dative coding.

More rarely, DOM is also seen to include cases where both objects bear non-zero marking triggered by animacy/definiteness, cf.

Finnish (personal knowledge)

(11a) $Y k \ddot{a} \quad n a ̈ k-i \quad$ poja-t

Ykä.NOM see-3SG.PAST boy-PL.ACC

'Ykä saw the boys'

(11b) Ykä näk-i poik-i-a Ykä.NOM see-3SG.PAST boy-PL-PART

'Ykä saw some boys'

In Finnish, objects of transitive clauses are never zeromarked, but similarly to (10), the object coding varies depending on definiteness (but not animacy); definite objects bear accusative coding, while indefinite objects are coded by the partitive.

DRM, for its part, is more heterogeneous than DOM, which is also manifested in the role of zero vs. explicit marking. Examples are given in (12)-(14) (see also (8), (9) above):

Korean (examples courtesy of Jae Jung Song)
(12a) kica-ka enehakca-eykey
journalist-NOM linguist-to
chayk-ul
book-ACC
'The journalist sent a/the book to the linguist'
(12b) kica-ka wellingten-ulo
journalist-NOM Wellington-to book-ACC
chayk-ul
'The journalist sent a/the book to Wellington'
(12c) kica-ka enehakca-lul chayk-ul journalist-NOM linguist-ACC book-ACC
'The journalist sent a/the book to the linguist'
(12d) *kica-ka wellingten-ul
chayk-ul journalist-NOM Wellington-ACC book-ACC

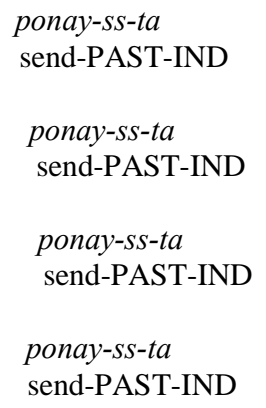

ponay-ss-ta send-PAST-IND (The journalist sent a/the book to Wellington)

Indonesian (examples courtesy of I Wayan Arka)

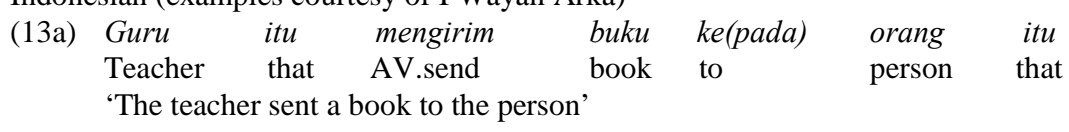




$\begin{aligned} & \text { (13b) Guru } \quad \text { itu } \text { mengirim } \\ & \text { Teacher that AV.send }\end{aligned}$ bukuke/*kepada
'The teacher sent a book Indonesia'

In Korean, DRM is manifested in various ways. First, there are differences between two case markers; -eykey is used for animate R's and -ulo for inanimate R's. Second, animate and inanimate R's are distinguished by dative shift, which is applicable to animate R's only. In Indonesian, animate and inanimate R's are preceded by different prepositions. There is no zero marking available for $\mathrm{R}$ arguments. Finally in Kikuyu, the variation is very much the same as in DOM as regards the zero vs. explicit marking of arguments; R bears more elaborate coding in (14b) based on the animacy of T. The central difference to DOM is found in (12) and (13), where the variation is between two explicitly marked objects, not between zero and overt marking.

\section{Differences in Syntactic Status of Arguments}

The differences in the zero vs. explicit marking of objects are rather directly related to the second difference between DOM and DRM, namely the core vs. peripheral nature of objects. In DOM, both animate and inanimate objects can be seen as objects in case the objects are explicitly expressed (see, however, Næss, 2003 for more drastic differences between animate/definite and inanimate/indefinite objects). This means that irrespecve of their zero vs. explicit marking, objects are best seen as direct objects and thus as parts of the clause core in cases such as (4) and (5), for example. DRM differs profoundly from DOM in this respect. First, there are languages, such as Korku and Korean, where only animate R's can be seen as parts of the clause core and inanimate R's are best seen as non-core obliques. These kinds of differences are found also in languages displaying DRM in the sense defined by Haspelmath (see (6) and (7)). Sec$\mathrm{d}$, in languages like Balinese, the relevant arguments are always obliques, i.e. the differences between core and periphery are not relevant. Moreover, it is very difficult to argue for the higher syntactic status of either animate or inanimate R's in cases such as (9), where the only difference between R's is the preposition used for their marking.

The differences in syntactic status of arguments between DOM and DRM are predicted; more significant formal differences indicate more evident differences in the status of arguments. The differences also have a semantic basis, as will be discussed in the next section. DOM and DRM have in common that animate objects constitute parts of clause core (in case any object does), while only in DOM inanimate objects may be seen as parts of clause core. The two types could therefore be distinguished based on the formal treatment of inanimate objects. We may add that in DRM certain verbs, most notably 'give', usually select core-like marked R's (in case this is possible in a given language), while other verbs (e.g. 'send') allow variation. This is relevant to the discussion in this paper in that recipients of 'give' are often parts of the verb valency, which also applies to direct objects of transitive verbs (see Kittilä, 2006a for a more thorough discussion of this).

\section{Optionality of Marking}

The third type of differences discussed here is presented by optionality. As shown above, animate objects are only optionally marked in many instances of DOM. This means that the more elaborate marking of animate objects is not an obligatory feature of grammar, but is often triggered rather by pragmatics and context. The lack of marking with an animate object does not necessarily result in ungrammaticality. In DRM, for its part, the differences are more often grammatically required. The freedom of choice exercised by the speaker is lacking and a failure to mark R's according to animacy may yield an ungrammatical construction. This is especially evident in cases, such as (9) and (12), where the variation is between two different instances of overt marking. Also instances of DRM triggered by animacy/definiteness of $\mathrm{T}$ seem obligatory if $\mathrm{T}$ is animate/definite (see (7) and (14)). The only instances of optionality in the case of DRM are found in languages where DRM is manifested via dative shift, as in English or Fongbe illustrated in (15):

Fongbe (Lefebvre \& Brousseau, 2002: p. 445f, 448f, 422)

(15a) kòkú só àsón ó ná Àsíbá

Kokutake crab DEF give Asiba

'Koku gave the crab to Asiba'

(15b)kòku só àkwé ná kùtònû Koku take money give Cotonou 'Koku gave money to Cotonou (a place name)'

(15c) kòkú ná Àsíbá àsón Koku give Asiba crab 'Koku gave Asiba crab'

(15d)*kòku ná kùtònû àkwé Koku give Cotonou money (Koku gave Cotonou money)

In Fongbe (and English), only animate R's allow dative shift and can thus be seen as parts of the clause core. The marking of animacy-determined differences is optional in the sense that dative shift is possible, but not obligatory, for animate R's.

One reason for the uneven distribution of optionality may be found in the nature of arguments involved in the variation. In $\mathrm{DOM}$, the variation is between zero marking and grammatical case (typically accusative). Consequently, we do not lose any non-retrievable information if the marking is omitted. The (un) marked argument is interpreted as a direct object regardless of its marking, since the object acquires its semantic role largely from the verb. On the other hand, DRM is often between two explicitly marked forms, typically semantic cases (such as allative and dative). This has the consequence that the risk of losing important, contextually non-retrievable information is greater than in DOM. Moreover, the markers involved in the variation (i.e. semantic cases and adpositions) are semantically richer in DRM, which makes them incompatible with semantically infe- 
licitous objects. For example, an adposition used for coding inanimate R's (and consequently the semantic role of Goal) cannot appear with animate R's (and the semantic role of Recipient) due to the semantic discrepancy between the marker and the marked argument.

\section{Functional Differences}

\section{Preliminaries}

In this section, the differences between DOM and DRM are discussed from a functional perspective. The functions considered include the following:

1) (The interplay of) Semantic role and animacy

2) Indexing

3) Discrimination

4) Effects of animacy and definiteness

These features have been chosen, since they are relevant to argument marking in general. The features will be discussed below in the order they appear above.

\section{Semantic Role and Animacy}

DOM and DRM display evident differences as regards their consequences for the semantic role borne by the affected arguments. In DOM, the semantic role of the object is maintained regardless of the differences in coding, while DRM phenomena are split in this respect (the two types are affected in different ways).

DOM affects the marking of direct objects typically bearing the role of patient (other roles, such as stimulus are also possible). Patients are typically inanimate and indefinite, a claim made, for example, by Comrie (1989: p. 128). This claim is both true and false. First, it is true that inanimate entities more naturally bear the role of patient, since they lack the capability of instigating events with intention. They are thus rather atypical agents, even though they can also be seen as causers of many events (as in 'the falling rock hit the child'). Second, however, it is disputable whether inanimate entities are more canonical patients than animate entities. Both inanimate and animate entities may be affected participants, which makes them both potential targets of events. The nature of affectedness varies according to animacy, but it is less clear whether inanimate patients constitute more affected and hence more typical patients. Even the opposite claim has been made by Næss (Næss, 2003) who claims that animate patients are actually prototypical (i.e. more affected) patients, which explains DOM. Despite the differences in the nature and degree of affectedness, both animate and inanimate entities are potential patients, which mean that differences in animacy do not have any bearing on the role of the relevant participants per se.

The effects of animacy on the semantic role of the affected argument are clearly more visible in DRM. Moreover, the two types of DRM are clearly split in this regard. The first type of DRM (Haspelmath, 2007) is closer to DOM as regards the interplay of animacy and semantic role. This is expected, since also the features of $\mathrm{T}$ contribute to the changes in $\mathrm{R}$ coding. In (7), for example, animacy of $\mathrm{R}$ is maintained. We may, however, speculate about the nature of reception in some cases: does the (in)animacy of the theme affect the nature of reception? Typically we conceptualize recipient as an animate participant that receives an inanimate theme (see e.g. Sedlak, 1975; Newman, 1996) transferred to its sphere of control. Animate entities (especially humans) are not as readily possessed by other animate entities. This may have consequences for the nature of reception if the theme is animate. On the other hand, in the second type of DRM, animacy has clear consequences for the semantic roles borne by R. Only animate participants may be seen as genuine recipients. This follows, since true reception entails active participation, which is possible only for animate entities. The lack of animacy thus implies an evident change in the role borne by R. Inanimate R's are rather seen as goals that are, similarly to recipients, endpoints of transfer (or motion), but in contrast to recipients, true reception is lacking for goals. We may add that recipients and goals differ according to their core vs. peripheral nature in events. Recipients are often integral (core) parts of events, while goals are more often peripheral (and optional) participants. For example, 'give' is not a complete event without a (human) recipient, while with, e.g., 'throw' a goal argument only specifies the endpoint of transfer. The event is possible also without a specified goal. We are not dealing with mere animacy differences in DRM, but animacy has more dramatic consequences for the referents of arguments. The more thorough formal changes discussed in Section 3.2 thus have a semantic basis in the second type of DRM.

\section{Indexing}

A further function given for argument marking has been labeled indexing (see, e.g., Song, 2001: pp. 159-165). Indexing means that the primary function of argument marking is not to distinguish between agent and patient (i.e. to indicate "who is doing what to whom"), but to highlight the semantic closeness of arguments to the prototype of a given role. For example, typical patients bear accusative coding, because they are close to the patient prototype. Indexing is rather close to semantic roles, but the notion is approached primarily from the viewpoint of prototypes in this section. This means that the focus lies on whether the marked arguments are better representatives of the role they mark than the differently marked objects.

DOM phenomena have been explained by referring to indexing by, for example, Comrie (1989), Aissen (2003) and Næss (2003). Comrie (1989: p. 128) and Aissen (2003) suggest that patients are typically inanimate and indefinite, whence the function of DOM is to highlight the unorthodox nature of animate patients (this can be seen as a kind of reversed indexing, the less typical role is more elaborately marked). Næss (2003: p. 1203), on the other hand, argues that DOM is better explained by affectedness and thus indexing (prototypical patients are affected participants): animate patients bear more elaborate coding than inanimate patients due to their higher degree of affectedness. The semantic role of the affected argument does not change in any evident way in DOM, which makes indexing functions possible. In other words, changes in coding do not have the function of distinguishing between clearly distinct roles, and they can thus code more subtle differences.

DRM differs from DOM also in this regard. In the first type of DRM, the role of recipient is largely maintained despite the evident formal differences in the coding of arguments. Indexing is thus helpful for explaining the differences in R coding. In the second type of DRM, we could claim that typical goals are also recipients (i.e., it is typical of goals to bear the role of recipient as well), which would then explain their core-like formal treatment in languages such as Korku and Korean. However, in this case we would have to account for the typical relation between goal and recipient, which does not seem plausible. Instead, it seems more appropriate to claim that we are dealing with two roles (goal and recipient) with their own kind of marking. In order that we could speak of indexing, there should be variation within the roles (e.g. variation between animate and inanimate 
recipients), not only between them. Indexing functions do thus not help us to explain the differences in the coding of R's.

\section{Discrimination}

Discrimination refers to cases where (explicit) argument marking has the function of expressing 'who is doing what to whom', i.e. marking is employed for distinguishing between agent and patient, or subject and object, depending on whether we are dealing with meaning or form (see Song, 2001: pp. 166-170).

It should come as no surprise that discrimination between agent and patient has been offered as an explanation for DOM. In case we have two animate participants, both of which are potential (and expected) agents in the denoted event, explicit coding of arguments is often the only (or at least the most secure and unambiguous) way of distinguishing between agent and patient. This function is very evident in the case of two animate participants, but it does not account for the marking of definite inanimates in an equally satisfactory manner. However, it is clear that discrimination (ambiguity avoidance) contributes to the occurrence of DOM.

The two instances of DRM are also here clearly split as regards the discriminatory functions of argument marking. The first type DRM is closer to DOM in this regard, and we may explain the changes in $\mathrm{R}$ coding by referring to discrimination in some cases. This is especially evident in cases such as the teacher sent the boy to the girl with two animate objects. The expected role of both animate participants is recipient, and explicit marking is needed for highlighting which participant bears this role. The only difference to DOM is that we are dealing with discrimination between animate theme and recipeent, not agent and patient. Differently from DOM, the marking is not iconic in DRM, since changes in the nature of Theme have consequences for R coding in cases such as (7) from Akan. On the other hand, discrimination does not contribute to the second type of DRM in any significant way. This is most evident in languages in which animate R's bear direct object-like coding. These languages usually also display DOM, which often results in an identical coding of the two objects, which clearly militates against the principles of discrimination. Moreover, variation between two explicit ways of marking (two adpositions or case forms) cannot be explained by discrimination, since a sufficient distinction is assured without further changes in marking.

\section{Animacy vs. Definiteness}

Finally, DOM and DRM can also be distinguished based on the effects of animacy and definiteness. As has been shown above, DOM can be triggered both by animacy and definiteness. The same applies to the first type of DRM, where animacy or definiteness of $\mathrm{T}$ can trigger formal changes in $\mathrm{R}$ coding. Also the slot occupied by $\mathrm{R}$ on the nominal hierarchies may be relevant, as (6) shows. On the other hand, in the second type of DRM only animacy is relevant to the coding of R's. Reasons for this uneven distribution of animacy and definiteness will be discussed below.

First, explicit marking of animate patients is expected, since this often has a disambiguating function, as was noted above. The marking of definite patients may appear as less expected at first; explicit disambiguation is not necessary between animate agents and definite patients, because animacy usually resolves potential ambiguity. However, as has been noted, for example, by Comrie (1989: p. 128), subjects (A) are typically animate and definite, while objects $(\mathrm{P} / \mathrm{O})$ constitute the opposite of this.
Indefiniteness is thus an expected feature of $\mathrm{P}$, which is left unmarked, while the opposite (the less expected case) is marked. The effects of animacy on the coding of $\mathrm{R}$ in the first type of DRM is also only natural, since the marking is in many cases also needed for resolving disambiguation, as noted above. Similarly to DOM, the consequences definiteness has for R coding are not as easily accounted for, since they seem to lack a clearly defined function, such as disambiguation. One of the reasons for the attested changes may, however, be found in the avoidance of two identically coded object arguments. In case a language has definiteness-based DOM that also applies to T arguments, the result would be two identically coded object arguments (Theme and Recipient), which can be avoided by modifying the marking of R.

The second type of DRM differs drastically from the types discussed thus far. There are many languages in which animacy determines the coding of R's, which is understandable, since, as noted above, animacy also has consequences for the semantic role borne by R's. Distinct marking of semantic roles may be redundant in some cases, but on the other hand, it is only natural that languages accord different semantic roles a different formal treatment. On the other hand, there are only very few languages in which definiteness if $\mathrm{R}$ has formal consequences. The only clear example of this I have come across is illustrated in (16) from Wolaitta:

Wolaitta (examples courtesy of Azeb Amha)

$\begin{array}{lll}\text { (16) ? } \begin{array}{l}\text { astamareé } \\ \text { teacher:M:NOM book:M:ACC }\end{array} & \text { 3:LOG bureau-M:ACC } \\ \text { /mat=aáfa } & \text { keettá } & \text { yedd-iisi } \\ \text { book } & \text { house:ABS } & \text { send-3MSG:PERF }\end{array}$

'The teacher sent the book to his office/to a library'

In Wolaitta, indefinite (inanimate) R's appear in the unmarked absolutive case, while definite (inanimate) R's bear accusative coding. Animate R's bear dative coding.

As noted above, languages like Wolaitta are clearly in the minority cross-linguistically, while animacy triggers changes in $\mathrm{R}$ coding in numerous languages. This very uneven distribution is rather straightforwardly accounted for by the nature of R's. Differently from Patients and Themes, $\mathrm{R}$ arguments have an expected animacy value: recipients are typically animate, while Goals are typically inanimate. Animacy is typically associated with definiteness, which renders recipients also definite and definiteness an expected feature of Recipients. This makes explicit coding of definiteness superfluous and it is thus not attested. What is also interesting that there are no languages in which indefiniteness of R's (i.e. the unexpected value) would be marked, either. In a similar vein, languages where indefiniteness of patients is marked in DOM are also very rare. We may also add that similar kind of marking is found for agents. Agents are also typically animate, and inanimacy is an unexpected feature that receives explicit coding in a number of languages (see, e.g., Delancey, 1984). Similarly to R's, there are only few languages in which definiteness has consequences for agent coding (see Meakins, 2009 for Gurindji Kriol, and Chelliah, 2009 for Meithei). This may be explained by the expected animacy of agents, which renders marking of definiteness redundant. Based on this, we may make the (preliminary) claim that definiteness is relevant to coding of arguments only with inanimate entities. Definiteness is thus marked only if it is not an expected feature.

\section{Discussion}

The general picture that emerges from the previous discus- 
sions is that differential marking of objects is not a uniform phenomenon, but the illustrated types can be distinguished based on both formal and functional criteria. The formal and functional features of the discussed types are illustrated schematically in Figure 1.

As the figure shows, the three object marking types can be distinguished from each other based on the discussed criteria. However, on a closer inspection, more interesting similarities and differences arise. First, formally the two instances of DRM are closer to each other than to DOM. This is not unduly surprising, since the types can be distinguished based on the element whose marking is modified. Despite this, DRM is not a uniform phenomenon formally, but the two types also display differences in the distribution of zero vs. explicit marking and optionality of marking.

What is more interesting in the present context is the functional motivation of the discussed types of object marking. The picture that emerges is that DOM and DRM 1 go more together and they are clearly distinct from DRM 2. This may appear unexpected at first given the formal features shared by the two instances of DRM. However, the attested distribution of functional features becomes understandable if we consider the fact that DOM and DRM 1 can both be said to be triggered by the features of the direct object (comprising Patient and Theme), while DRM 2 is determined by features of $\mathrm{R}$ alone. The main difference between DOM and DRM 1 is that the changes triggered by the direct object are expressed on the Patient in DOM and on R in DRM 1. The question that remains is why the changes triggered by the direct object referent are marked on different arguments. In DOM, the most natural candidate for highlighting the differences is the direct object. In some languages (such as Tauya, see MacDonald 1990: p. 120), similar disambiguation is achieved by modifying the Agent. In DRM 1, in turn, there are two (in principle) equally plausible candidates for expressing the given differences. The iconic solution would be to mark the changes on the Theme, since Theme is the argument whose features are affected. However, as has been noted above, formal changes occurring in DRM 1 also due to disambiguation, which renders the Theme a non-optimal locus

\section{DOM DRM $1 \quad$ DRM 2}

Form

\begin{tabular}{|c|c|c|c|}
\hline $\begin{array}{l}\text { Zero vs. explicit } \\
\text { marking }\end{array}$ & + & $(+)$ & - \\
\hline Core vs. periphery & - & + & + \\
\hline Optionality & + & - & $(-)$ \\
\hline \multicolumn{4}{|l|}{ Function } \\
\hline $\begin{array}{l}\text { Changes in seman- } \\
\text { tic role }\end{array}$ & - & - & + \\
\hline Indexing & + & $(-)$ & $(+)$ \\
\hline Discrimination & + & + & - \\
\hline $\begin{array}{l}\text { Animacy + defi- } \\
\text { niteness }\end{array}$ & Both & Both & Animacy \\
\hline
\end{tabular}

Figure 1.

Schematic illustration of the three objects marking types. for marking the relevant changes. $\mathrm{T}$ and $\mathrm{R}$ are not distinguished in a sufficient manner in case the Theme is marked (modifying the marking of the Theme is possible, but clearly less widely attested than marking the changes on R, see Kittilä, 2006b for a more detailed discussion). The result is a construction with two identically marked objects in case the given language accords the $\mathrm{R}$ argument the same formal treatment as the direct object. On the other hand, marking the $\mathrm{R}$ according to its role, e.g. by a preposition, always resolves possible ambiguity, which explains why languages resort to this if additional disambiguating mechanisms are necessary. Moreover, many languages have a mechanism readily available for coding $\mathrm{R}$ (or motion in more general terms), which can be resorted to when explicit formal distinction is necessary.

To summarize. Differential marking of objects is not a uniform phenomenon that could always be described by the same criteria. The three types of object marking discussed in this paper share common features, but they also display differences. DOM and DRM 2 can be seen as the extreme types of differential marking of objects that are clearly different phenomena distinguishable based on most of the formal and functional criteria discussed in Sections 3 and 4. This is only understandable, since features of different arguments are responsible for the attested differences. DRM 1, in turn, can be seen as an intermediate between the two other types. Formally, it has more features in common with DRM 2, while functionally it is closer to DOM. This is easily accounted for, since formally the changes are expressed on the $\mathrm{R}$ argument, but functionally features of $\mathrm{T}$ are also relevant to the attested changes. Depending on which features (formal or functional) we emphasize, DRM 1 can be grouped with either DOM or DRM 2. Typologists (and linguists in general) are typically looking for functional similarities and differences between constructions, which would make it more natural to view DOM and DRM 1 as subtypes of the same phenomenon, and distinct from DRM 2. This distinction can be based on the triggering factor, i.e. features of the direct object referent (DOM and DRM 1) vs. features of R only (DRM 2). We can thus speak of Differential marking of objects triggered by direct object and differential object marking triggered by R. This distinction is functionally motivated and provides us with better new insights into the functions of argument marking than a distinction based on formal features only. The first type (DOM and DRM1) is best explained by discrimination, while the second type (DRM 2) is better accounted for by indexing.

\section{Acknowledgements}

I thank the anonymous referees of this paper for their invaluable comments on an earlier version of this paper. I would also like to express my gratitude to Academy of Finland (grant $1,127,724)$ for providing funding for the present study.

\section{References}

Aissen, J. (2003). Differential object marking: Iconicity vs. economy. Natural Language and Linguistic Theory, 21, 435-483. doi:10.1023/A:1024109008573

Blansitt, E. Jr. (1973). Bitransitive clauses. Working Papers on Language Universals, Stanford: Stanford University.

Bossong, G. (1985). Empirische universalienforschung: Differentielle objektmarkierung in den neuiranischen Sprachen. Tübingen: Narr.

Chelliah, S. (2009). Semantic role to new information in Meithei. In J. Barðdal, \& S. Chelliah (Eds.), The role of semantic, pragmatic, and 
discourse factors in the development of case (pp. 377-400). Amsterdam/Philadelphia: Benjamins.

Comrie, B. (1989). Language universals and linguistic typology (2nd ed.). Chicago, IL: University of Chicago Press.

Ebert, K. (1997). Camling. München/Newcastle: Lincom Europa.

Gair, J. W., \& Paolillo, J. C. (1997). Sinhala. München/Newcastle: Lincom Europa.

Gasser, M. (1983). Topic continuity in written Amharic narrative. In T. Givón (Ed.), Topic continuity in discourse: A quantitative crosslanguage study (pp. 95-139). Amsterdam/Philadelphia: John Benjamins.

Haspelmath, M. (2007). Ditransitive alignment splits and inverse alignment. Functions of Language, 14, 79-102.doi:10.1075/fol.14.1.06has

Kittilä, S. (2006a). The anomaly of the verb 'give' explained by its high (formal and semantic) transitivity. Linguistics, 44, 569-612.

Kittilä, S. (2006b). The woman showed the baby to her sister: On resolving humanness-driven ambiguity in ditransitives. In L. Kulikov, A. Malchukov, \& P. de Swart (Eds.), Case valency and transitivity (pp. 291-308). Amsterdam/Philadelphia: Benjamins.

Kittilä, S. (2007). On the encoding of transitivity-related features on the indirect object. Functions of Language, 14, 149-164.

Kittilä, S. (2008). Animacy effects on differential Goal Marking. Linguistic Typology, 12, 245-268.

Lazard, G. (1998). Actancy. Berlin/New York: Mouton de Gruyter. doi:10.1515/9783110808100

Lefebvre, C. \& Brousseau, A-M. (2002). A grammar of Fongbe. Berlin/New York: Mouton de Gruyter.

MacDonald, L. (1990). A grammar of Tauya. Berlin/New York: Mouton de Gruyter.

Meakins, F. (2009). The case of the shifty ergative marker: A pragmatic shift in the ergative marker of one Australian mixed language. In J.
Barðdal, \& S. Chelliah (Eds.), The role of semantic, pragmatic, and discourse factors in the development of case (pp. 59-91). Amsterdam/Philadelphia: Benjamins.

Mohanan, T. (1994). Argument structure in Hindi. Stanford, CA: CSLI Publications.

Moyse-Faurie, C. (1983). Le drehu, langue de Lifou (Iles Loyauté). Paris: SELAF.

Næss, Å. (2003). What markedness marks: The markedness problem with direct objects. Lingua, 114, 1186-1212.

Næss, Å. (2007). Prototypical transitivity. Amsterdam/Philadelphia: Benjamins.

Nagaraja, K. S. (1999). Korku language: Grammar, texts and vocabulary. Tokyo: Institute for the Study of Languages and Cultures of Asia and Africa.

Newman, J. (1996). Give: A cognitive linguistic study. Berlin/New York: Mouton de Gruyter.

Pilot-Raichoor, C. (1991). Le badaga, langue dravidienne: description et analyse. Ph.D. Thesis, Paris: University of Paris III.

Pilot-Raichoor, C. (1994). L'objet en badaga. Bulletin de la Société de Linguistique de Paris, 89, 359-397.

Sáàh, K., \& Ézè, É. (1997). Double objects in Àkán amd Ìgbo. In R. Déchaine, \& V. Manfredi (Eds.), Object positions in Benue-Kwa (pp. 139-151). The Hague: Holland Academic Graphics.

Sedlak, P. A. S. (1975). Direct/indirect object word order: A crosslinguistic analysis. Working Papers on Language Universals, Los Angeles: University of Southern California.

Song, J-J. (2001). Linguistic typology: Morphology and syntax. Harlow \& London: Pearson Education.

Taylor, J. (1985). Nkore-Kiga. London: Routledge.

\section{Appendix}

\section{Abbreviations}

$\begin{array}{ll}\text { ABL } & \text { Ablative case } \\ \text { ABS } & \text { Absolutive case } \\ \text { ACC } & \text { Accusative case } \\ \text { AV } & \text { Active voice } \\ \text { DAT } & \text { Dative case } \\ \text { DEF } & \text { Definite } \\ \text { ERG } & \text { Ergative case } \\ \text { IND } & \text { Indicative } \\ \text { INSTR } & \text { Instrumental case } \\ \text { LOC } & \text { Locative case } \\ \text { LOG } & \text { Logophoric } \\ \text { M } & \text { Masculine }\end{array}$

$\begin{array}{ll}\text { NOM } & \text { Nominative case } \\ \text { OBJ } & \text { Object marker } \\ \text { PART } & \text { Partitive case } \\ \text { PAST } & \text { Past tense } \\ \text { PERF } & \text { Perfective } \\ \text { PERS } & \text { Person marker } \\ \text { PL } & \text { Plural } \\ \text { PN } & \text { Personal name } \\ \text { PRES } & \text { Present tense } \\ \text { RP } & \text { Recent past } \\ \text { SG } & \text { Singular } \\ \text { TP } & \text { Today past }\end{array}$

